\title{
ASO Author Reflections: Anastomotic Leaks After Esophagectomy-No Impact on Long-Term Survival
}

\author{
Sivesh K. Kamarajah, BMedSci, MBChB ${ }^{1,2}$, and Alexander W. Phillips, MD, MA ${ }^{1,2,3}$ 믄 \\ ${ }^{1}$ Northern Oesophagogastric Unit, Royal Victoria Infirmary, Newcastle upon Tyne NHS Foundation Trust, Newcastle- \\ upon-Tyne, UK; ${ }^{2}$ Institute of Cellular Medicine, Newcastle University, Newcastle-upon-Tyne, UK; ${ }^{3}$ School of Medical \\ Education, Newcastle University, Newcastle upon Tyne, UK
}

\section{PAST}

Anastomotic leak remains a common complication after esophagectomy. It is associated with perioperative mortality and prolonged hospital stay. Some have suggested that it may also contribute towards poorer long-term survival, although the mechanism is unclear. A French multicenter study defined severe esophageal leak (SEAL) as that which equated to a grade III/IV Clavien-Dindo complication. This study demonstrated a poorer long-term prognosis in patients who developed SEAL following esophagectomy; ${ }^{1}$ however, the study was limited by a very heterogenous population and did not report on recurrencefree survival. The question thus remains, does anastomotic leak negatively influence long-term survival in patients undergoing esophagectomy for cancer?

\section{PRESENT}

The present study evaluates outcomes from a single center over a 20 -year period. ${ }^{2}$ Complications are recorded contemporaneously, as are patient outcomes. Oncological management decisions were made by a single multidisciplinary team, and surgical technique was standardized

ASO Author Reflections is a brief invited commentary on the article "Anastomotic leak does not impact on long-term outcomes in esophageal cancer patients". Ann Surg Oncol. https://doi.org/10.12 45/s10434-020-08199-x.

(C) The Author(s) 2020

First Received: 2 January 2020; Published Online: 23 January 2020

A. W. Phillips, MD, MA

e-mail: awphillips@doctors.net.uk across those operating. This involved a radical two-field lymphadenectomy permitted by a transthoracic route. ${ }^{3}$ The consistency of these factors potentially increases the validity of these results in centers that have a similar surgical ethos. It may be that a radical lymphadenectomy, ${ }^{4}$ which was routinely performed within this study, negated any potential adverse effects on long-term prognosis. Reassuringly anastomotic leak, irrespective of severity, had no bearing on long-term survival. This is an important consideration for both patients and clinicians, allowing appropriate counselling and reassurance.

\section{FUTURE}

These data may help allay fears that anastomotic leak may potentially contribute towards poorer overall prognosis. The importance of managing leaks appropriately is vital for short-term outcomes. High-volume centers, by definition, have increased experience in managing such complications, and a judicious and aggressive strategy has been shown to lead to minimal risk of perioperative mortality from such leaks. ${ }^{5}$ However, techniques that might help prevent anastomotic leak remain a research priority. Concepts such as preconditioning and intraoperative use of indocyanine green to gauge conduit vascularity have all been employed but none have been able to eliminate the incidence of anastomotic leak. Further research into anastomotic techniques and adjuncts that can minimize leak occurrence or diminish their short-term impact are required.

DISCLOSURE The authors have no conflicts of interest to disclose. 
OPEN ACCESS This article is licensed under a Creative Commons Attribution 4.0 International License, which permits use, sharing, adaptation, distribution and reproduction in any medium or format, as long as you give appropriate credit to the original author(s) and the source, provide a link to the Creative Commons licence, and indicate if changes were made. The images or other third party material in this article are included in the article's Creative Commons licence, unless indicated otherwise in a credit line to the material. If material is not included in the article's Creative Commons licence and your intended use is not permitted by statutory regulation or exceeds the permitted use, you will need to obtain permission directly from the copyright holder. To view a copy of this licence, visit http://creativecommons. org/licenses/by/4.0/.

\section{REFERENCES}

1. Markar S, Gronnier C, Duhamel A, et al. The impact of severe anastomotic leak on long-term survival and cancer recurrence after surgical resection for esophageal malignancy. Ann Surg. 2015;262(6):972-80.
2. Kamarajah SK, Navidi M, Wahed S, et al. Anastomotic leak does not impact on long-term outcomes in esophageal cancer patients. Ann Surg Oncol. https://doi.org/10.1245/s10434-020-08199-x.

3. Phillips AW, Dent B, Navidi M, Immanuel A, Griffin SM. Trainee involvement in Ivor Lewis esophagectomy does not negatively impact outcomes. Ann Surg. 2018;267(1):94-8.

4. Phillips AW, Hardy K, Navidi M, Kamarajah SK, Madhavan A, Immanuel A, et al. Impact of lymphadenectomy on survival after unimodality transthoracic esophagectomy for adenocarcinoma of esophagus. Ann Surg Oncol. Epub 11 Oct 2019. https://doi.org/10. 1245/s10434-019-07905-8.

5. Dent B, Griffin SM, Jones R, Wahed S, Immanuel A, Hayes N. Management and outcomes of anastomotic leaks after oesophagectomy. Br J Surg. 2016;103(8):1033-8.

Publisher's Note Springer Nature remains neutral with regard to jurisdictional claims in published maps and institutional affiliations. 